\section{BMJ Open Respiratory Research}

\title{
Determinants of poor inhaler technique and poor therapy adherence in obstructive lung diseases: a cross- sectional study in community pharmacies
}

\author{
Anna Vanoverschelde (D) , ${ }^{1,2}$ Paulien van der Wel, ${ }^{1}$ Barbara Putman (D) ,1,3 \\ Lies Lahousse (D) 1,2
}

\begin{abstract}
To cite: Vanoverschelde $A$, van der Wel P, Putman B, et al. Determinants of poor inhaler technique and poor therapy adherence in obstructive lung diseases: a cross-sectional study in community pharmacies. BMJ Open Resp Res 2021;8:e000823. doi:10.1136/ bmjresp-2020-000823
\end{abstract}

Received 3 November 2020 Accepted 11 July 2021
Check for updates

(C) Author(s) (or their employer(s)) 2021. Re-use permitted under CC BY-NC. No commercial re-use. See rights and permissions. Published by BMJ.

${ }^{1}$ Department of Bioanalysis, Ghent University, Ghent, Belgium

${ }^{2}$ Department of Epidemiology, Erasmus Medical Center Rotterdam, Zuid-Holland, The Netherlands

${ }^{3}$ Department of Medicine and Department of Environmental Medicine, New York University School of Medicine, New York New York, USA

Correspondence to Professor Lies Lahousse; lies.lahousse@ugent.be

\section{ABSTRACT}

Background Correct inhaler use can be challenging in real life, with incorrect use resulting in poor symptom control. The aim of this study was to examine factors associated with poor inhaler technique and poor therapy adherence among patients with obstructive lung disease in community pharmacies.

Methods A cross-sectional study was conducted in patients with obstructive lung diseases in nine Belgian community pharmacies. Logistic regression analyses identified factors associated with poor inhaler technique and poor therapy adherence (assessed by the Test of Adherence to Inhalers and the modified Medication Possession Ratio).

Results Seventy obstructively impaired community patients (median age $64 \mathrm{y}, 56 \%$ females) were included and the technique of 122 inhalers was assessed. Inhaler technique scored generally poor, with half of patients making critical errors in using at least one of their inhalers. In multivariable analysis, the use of multiple devices (adjusted OR, aOR 11.68; $95 \% \mathrm{Cl} 3.29$ to 41.51) and a diagnosis of asthmaChronic Obstructive Pulmonary Disease overlap (ACO; aOR $7.06 ; 95 \% \mathrm{Cl} 1.15$ to 43.35 ), were associated with making critical errors in inhaler technique independent of quality of life. Non-adherence occurred in more than one-third of patients, and occurred in up to one half of the patients when also taking overuse into account. In multivariable analysis for therapy adherence, current smoking was associated with poor therapy adherence (aOR $0.15 ; 95 \% \mathrm{Cl} 0.02$ to 0.96 ) independently of age and poor treatment knowledge. Therapy adherence was poor in patients with asthma compared with those with ACO. Current smokers and highly educated patients seemed to be at increased risk for inhaler overuse. Conclusions Given the important role of a correct inhaler technique and therapy adherence in disease control, these findings emphasise the need for patient education and aiming uniformity in the inhaler device.

Trial registration number B670201835229.

\section{INTRODUCTION}

Asthma and chronic obstructive pulmonary disease (COPD) are common diseases with increasing prevalence. ${ }^{1}$ In order to relieve patients' symptoms and prevent

\section{Key messages}

Which factors determine poor inhaler technique and poor therapy adherence in patients with obstructive lung disease in Belgian community pharmacies?

- Our study showed that the use of multiple devices and a diagnosis of asthma-chronic obstructive pulmonary disease overlap are independently and significantly associated with a poor inhaler technique. Smoking and highly educated young patients seemed to be at increased risk for inhaler overuse.

- This community pharmacy-based study identified factors associated with critical errors in inhaler technique and poor therapy adherence, which may facilitate to detect patients most at risk for poor control of their respiratory disease.

exacerbations, inhaler therapy is the cornerstone treatment. A successful inhaler treatment relies on several factors but is mainly dependent on a good inhaler technique and therapy adherence. ${ }^{23}$ A correct inhaler technique is crucial for optimal drug delivery to the lungs, ${ }^{4}$ and to avoid local side effects, such as oropharyngeal candidiasis, ${ }^{5}$ and dysphonia with the use of inhaled corticosteroids (ICS). ${ }^{6}$

Poor inhaler technique and poor adherence are major problems. WHO has estimated that only $50 \%$ of the chronic patients are adherent to long-term chronic therapies. ${ }^{7}$ According to the systematic review published in 2016 , only $31 \%$ of patients have been able to use an inhaler correctly, and the inhaler technique has not improved over the past 40 years. $^{8}$ After the launch of pressurised metered-dose inhalers (pMDI) in the 1960s, other devices have been developed such as dry powder inhalers (DPI) and Respimat Soft Mist inhalers (SMI). Despite innovations in devices and tools to support coordination, a 
correct inhaler technique remains challenging in real life. $^{8}$

The type of inhaler is an important determinant of incorrect inhaler technique. ${ }^{9}$ Patient-related factors such as age ${ }^{10}$ COPD versus asthma diagnosis, ${ }^{11}$ emotional status $^{9}$ and healthcare-related factors such as never receiving inhaler instructions (from a physician or pharmacist), ${ }^{12} 13$ being treated in a group practice ${ }^{9}$ and the prescription of multiple inhaler devices have been associated with incorrect inhaler technique. ${ }^{12}$

A broad range of factors may influence therapy adherence including patient's age, comorbidities, knowledge about the treatment and disease, cost, adverse effects of medication and poor physician-patient communication. ${ }^{14}$ Consistent associations between therapy adherence and stronger inhaler-necessity beliefs and older age have been described before. ${ }^{15}$ Differences in adherence level and pattern between asthma and COPD patients have been investigated. ${ }^{16}$ However, little is known about the inhaler technique and adherence level among asthma-chronic obstructive pulmonary disease overlap (ACO) patients.

Previous studies have mainly investigated the determinants of poor inhaler technique in outpatient clinics, ${ }^{12} 17$ specialist respiratory service, ${ }^{13}$ chest clinics ${ }^{18}$ or in general practitioner practices. ${ }^{9}$ The aim of this study was to examine factors associated with poor inhaler technique and poor therapy adherence in patients with obstructive lung disease in community pharmacies. Detection of these determinants could help community pharmacists to identify patients most at-risk for poor inhaler technique or poor adherence.

\section{METHODS}

\section{Study design}

We used baseline data from 70 patients with obstructive lung diseases enrolled in a pragmatic randomised controlled trial to improve inhaler technique using mHealth conducted in Belgian community pharmacies. ${ }^{19}$

Patients were enrolled from nine community pharmacies (rural and urban, located in East-Flanders, Belgium) on 15 days during the study period (March-December 2018). The participating pharmacies invited their regular patients with asthma and/or COPD to the study research date at their regular pharmacy.

Adult patients with self-reported chronic asthma or COPD who used an inhaler for their condition, and had their medication dispensing history recorded in the pharmacy software, were eligible for inclusion. Patients with insufficient comprehension of the Dutch language were excluded. If patients were not willing or not able to give an informed consent, or did not agree to participate in further follow-up, they were also excluded from participation.

\section{Inhaler technique}

Patients' inhaler technique was rated by the investigator, using a checklist per device. These checklists consisted of all the essential steps (10 steps for DPIs and SMIs, 11 steps for pMDIs, and 12 steps for pMDI with valved holding chamber (VHC) and Autohaler). The inhaler score was calculated as the proportion of the number of correct steps to the total number of steps. Critical errors were defined as errors that by itself will significantly impair the delivery of the drug to the lungs ${ }^{20}$ (eg, not removing the cap of the device, not shaking a pMDI/Autohaler, not loading DPI/SMI/Autohaler correctly, or not inhaling vigorously and deeply through DPI). Shaking a pMDI was recommended to all patients to simplify patient education in real-life practice, even though shaking is unnecessary in case of a solution in hydrofluoroalkane devices. ${ }^{4}$ Sensitivity analyses were performed with failure to shake a pMDI considered as a non-critical error when formulated as a solution.

\section{Therapy adherence}

Therapy adherence was measured by the Test of the Adherence to Inhalers (TAI) questionnaire. The TAI has been developed and validated by researchers from the Integrated Research Programmes on Asthma and COPD of the Spanish Society of Pulmonology and Thoracic Surgery. This questionnaire is designed in order to identify patients with low adherence, to determine the level of adherence and the pattern of non-adherence. The 12-item TAI consists of 10 questions to be filled in by the patient (10-item TAI), and 2 questions for the healthcare professional. Patients with a score of less than 50 on the 10-item TAI were classified as being non-adherent. The questions for healthcare professionals are scored with 1 or 2 points for poor or good knowledge of the regimen and/or whether or not making critical inhaler errors, respectively. Poor treatment knowledge was defined as poor regimen knowledge and/or poor inhalation technique resulting in a score of less than 4 on item 11 to 12 with those scoring 4 as reference category. ${ }^{21} 22$

To objectively evaluate inhaler overuse and reduce social-desirability bias, the modified medication possession ratio (mMPR) was calculated based on the pharmacy dispensing data of the past year. The mMPR was calculated by dividing the total days' supply of all prescriptions for ICS, long-acting $\beta 2$-agonist (LABA) and/or long-acting muscarinic antagonist (LAMA) over a defined period by the sum of the days between first and last prescription, including the duration of the last prescription. ${ }^{23}$ An mMPR based on the defined daily dose (DDD) (mMPRddd) was calculated and averaged over all different inhalers. An mMPRddd of 80\%-120\% was considered as adherent. An mMPR below $80 \%$ was considered as underuse and above $120 \%$ as overuse.

\section{Covariables}

The handgrip strength, as a proxy for respiratory muscle strength, ${ }^{24}$ was measured using the hand dynamometer Hydraulic Jamar. The patient was asked to sit straight up with the elbow bent at $90^{\circ}$ and to squeeze with maximal strength. The handgrip strength of each hand was 
measured three times, and the mean value of the dominant hand was calculated. The handgrip strength \% predicted was calculated as the mean dominant handgrip strength of the patient divided by the right mean grip strength reference values of similar age and sex. ${ }^{25}$

Generic health status was assessed using the valuation section of the EuroQol five-dimension questionnaire on a score between 0 (worst imaginable health status) and 100 (best health status) on overall quality of life (QoL) ${ }^{26}$

Patient characteristics such as height, weight, education level, smoking status, respiratory diagnosis and adverse drug events were collected through self-report. Body mass index (BMI, $\mathrm{kg} / \mathrm{m}^{2}$ ) was calculated from weight and height. Education level was categorised into low education (primary education and lower secondary education) and high education level (upper secondary education and higher education).

If a patient used one or more inhalers of the same type (eg, two pMDIs), it was defined as using a single device. Patients using different types of inhalers (eg, a pMDI and a DPI) were defined as multiple inhalers.

\section{Statistical analysis}

In order to examine patients' characteristics, descriptive statistics were applied. Categorical variables were described as counts (n) with percentages. Continuous data were described as mean with SD when normally distributed and as median with IQR when not normally distributed.

Logistic regression analyses were undertaken to identify factors associated with critical inhaler errors and therapy non-adherence (TAI <50). Effect sizes were expressed in ORs with their 95\% CIs. The variables studied for predicting critical errors were: age ${ }^{10}$ respiratory diagnosis, ${ }^{11}$ the use of multiple devices, ${ }^{12}$ QoL, ${ }^{9}$ received inhaler instruction by pharmacist and/or physician before ${ }^{12}$ and handgrip strength. ${ }^{27}$ The variables studied for predicting non-adherence were: age, QoL, education level, poor treatment knowledge, the use of multiple devices, adverse events and smoking status. ${ }^{1528}$ A manual forward selection process was used to add factors with a $\mathrm{p}<0.15$. Additional logistic regression analyses were performed for poor therapy adherence, objectively defined as an mMPR $<80 \%$ or $>120 \%$. Model quality was assessed using the Hosmer and Lemeshow test, Nagelkerke $\mathrm{R}^{2}$ and classification table. Data analyses were performed using IBM SPSS Statistics V.25. P values $<0.05$ were considered significant (two sided). Post hoc power analysis was performed to determine the achieved power to reach statistical significance, based on the total sample size, the effect estimates, the observed R-square and alpha of 0.05. Statistical power was calculated using G*Power V.3.1.9.2.

\section{RESULTS}

\section{Patient characteristics}

Of the 122 subjects eligible for the study, 52 patients declined to participate and more than half $(n=70)$ agreed to participate. Sociodemographic and clinical characteristics of enrolled patients are presented in table 1 . The median age was 64 years, mean BMI $26 \mathrm{~kg} /$ $\mathrm{m}^{2}$ and $56 \%$ were female. In total, 31 patients had asthma (44\%), 27 COPD (39\%) and 12 ACO (17\%). About half of the patients reported at least one exacerbation in the previous year, requiring a hospitalisation in one out of five $(21 \%)$. Adverse drug events of inhaler therapy were reported in $43 \%(n=30)$. The most reported adverse drug events were a dry mouth $(n=16)$ and a hoarse voice $(n=13)$. Median number of chronic comedication was 2 for asthma patients and 5 for COPD or ACO patients (Kruskal-Wallis, $\mathrm{p}=0.020$ ).

\section{Inhaler technique}

In total, 133 inhalers were used by 70 patients. Two-thirds of the patients used more than one inhaler. About half of the patients used a single device $(n=38,54 \%)$ and the most commonly used device was a DPI (table 1 ).

Only $21 \%$ of patients reported that both their pharmacist and physician had taught them the inhaler technique before the start of the study $(\mathrm{n}=15)$. While their physician or their pharmacist, had instructed them on the inhaler technique in almost three quarters of patients $(n=50$, $71 \%$ ), still $7 \%$ reported not to have learnt the technique by any pharmacist or physician before the start of the study $(\mathrm{n}=5)$ (table 1$)$.

In total, 122 inhalers were scored regarding patient's inhaler technique, including DPIs $(\mathrm{n}=72)$, pMDIs $(n=33)$, SMIs $(n=11)$, pMDI with VHC $(n=5)$ and Autohaler $(n=1)$. The most frequent inhaler errors with DPI and pMDI were mistakes in posture, no full expiration before inhalation and no inspiration breath-hold (table 2). Inhaler technique scored generally poor with half of patients making critical errors in using at least one of their inhalers $(n=36,51 \%)$. Only one patient $(1.4 \%)$ performed a perfect inhaler technique. Among patients using a single device, the proportion of patients making critical errors was $23 \%(\mathrm{n}=7 / 30)$ in DPI users compared with $43 \%(\mathrm{n}=3 / 7)$ in pMDI users.

The proportion of patients making critical errors was $29 \%$ in patients using a single device compared with $75 \%$ in patients using two different devices, and $100 \%$ in patients with three different devices. For statistical analyses, patients with two or three different devices were analysed together as patients using multiple devices. Table 3 shows the variables associated with poor inhaler technique. In univariable analyses, ACO (OR 5.45; $95 \%$ CI 1.22 to 24.43 ), the use of multiple devices (OR 8.77; 95\% CI 2.94 to 26.14 ) and QoL (OR 0.96; 95\% CI 0.93 to 1.00 ) were significantly associated with making critical errors in inhaler technique. We investigated in a sensitivity analysis whether the association was not driven by frequent use of comedication in ACO patients. However, the association between ACO and poor inhaler technique remained after adjusting for the number of chronic comedication (OR 5.62; $95 \%$ CI 1.22; 25.96). No associations were found between age, received inhaler 
Table 1 Sociodemographic and clinical characteristics of the subjects

\begin{tabular}{|c|c|}
\hline & Total $(n=70)$ \\
\hline Age in years, median (Q1-Q3) & $64(55-73)$ \\
\hline Female, n (\%) & $39(56)$ \\
\hline $\mathrm{BMl}$ in $\mathrm{kg} / \mathrm{m}^{2}$, mean (SD) & $26(5)$ \\
\hline Asthma, $\mathrm{n}(\%)$ & $31(44)$ \\
\hline COPD, n (\%) & 27 (39) \\
\hline ACO, n (\%) & $12(17)$ \\
\hline Time since diagnosis in years, median (Q1-Q3) & $13(5-28)$ \\
\hline Never smoker, n (\%) & $24(34)$ \\
\hline Past smoker, n (\%) & $32(46)$ \\
\hline Current smoker, n (\%) & $14(20)$ \\
\hline $\begin{array}{l}\text { Pack-years among ever smokers, median } \\
\text { (Q1-Q3) }\end{array}$ & $30(11-42)$ \\
\hline Low education level, n (\%) & $28(40)$ \\
\hline High education level, n (\%) & $42(60)$ \\
\hline$\geq 1$ exacerbation in preceding year, n (\%) & $34(49)$ \\
\hline $\begin{array}{l}\geq 1 \text { severe exacerbation in preceding year, } n \\
(\%)\end{array}$ & $8(11)$ \\
\hline
\end{tabular}

Handgrip strength dominant hand in kg, mean 30 (11) (SD)

\begin{tabular}{lc}
\hline Handgrip strength \% predicted, mean (SD) & $92(24)$ \\
\hline One inhaler, n (\%) & $24(34)$ \\
\hline Two inhalers, n (\%) & $31(44)$ \\
\hline Three inhalers, n (\%) & $13(19)$ \\
\hline Four inhalers, n (\%) & $2(3)$ \\
\hline DPI(s), n (\%) & $30(43)$ \\
\hline MDI(s), n (\%) & $8(11)$ \\
\hline SMI(s) (combinations), n (\%) & $11(16)$ \\
\hline DPI+MDI, n (\%) & $21(30)$ \\
\hline Single device, n (\%) & $38(54)$ \\
\hline SABA, n (\%) & $11(16)$ \\
\hline SABA/SAMA, n (\%) & $22(31)$ \\
\hline ICS, n (\%) & $2(3)$ \\
\hline LABA, n (\%) & $2(3)$ \\
\hline ICS/LABA, n (\%) & $36(51)$ \\
\hline LABA/LAMA, n (\%) & $7(10)$ \\
\hline ICS/LABA/LAMA, n (\%) & $23(33)$ \\
\hline $\begin{array}{l}\text { Oral (leukotriene receptor antagonist or } \\
\text { theophylline), n (\%) }\end{array}$ & $13(19)$ \\
\hline Quality of life, mean (SD) & $69(16)$ \\
\hline $\begin{array}{l}\text { Received inhaler instruction from both } \\
\text { pharmacist and physician before, n (\%) }\end{array}$ & $15(21)$ \\
\hline Received inhaler instruction from pharmacist \\
or physician before, n (\%) & $50(71)$ \\
\hline peceived never inhaler instruction from & \\
\hline Adverse drug events, n (\%) & \\
\hline & \\
\hline
\end{tabular}

Table 1 Continued

\begin{tabular}{lc}
\hline & Total (n=70) \\
\hline Poor treatment knowledge, $\mathrm{n}(\%)$ & $40(57)$ \\
$\begin{array}{l}\text { Number of chronic comedication and } \\
\text { supplements, median (Q1-Q3) }\end{array}$ & $4(2-6)$ \\
\hline Most frequently used chronic drugs, n (\%) & \\
\hline Beta-blocking agents (C07) & $33(47)$ \\
\hline Drugs for acid-related disorders (A02) & $25(36)$ \\
Lipid-modifying agents (C10) & $23(33)$ \\
\hline Antithrombotic agents (B01) & $21(30)$ \\
\hline Psycholeptics (N05) & $17(24)$ \\
\hline $\begin{array}{l}\text { Agents acting on the renin-angiotensin } \\
\text { system (C09) }\end{array}$ & $15(21)$ \\
Antidepressants (N06A) & $13(19)$ \\
\hline
\end{tabular}

No missing data.

ACO, asthma-COPD overlap; BMI, body mass index; COPD, chronic obstructive pulmonary disease; DPI, dry powder inhaler; ICS, inhaled corticosteroids; LABA, long-acting $\beta_{2}$-agonist; LAMA, long-acting muscarinic antagonist; MDI, metered-dose inhalers; SABA, short-acting $\beta_{2}$-agonist; SAMA, short-acting muscarinic antagonist; $\mathrm{SMI}$, soft mist inhalers.

instruction or handgrip strength \% predicted and poor inhaler technique as the outcome. However, handgrip strength $\%$ predicted was significantly associated with inhaling vigorously and deeply in DPI users (OR 1.09; 95\% CI 1.02 to $1.17 ; \mathrm{p}=0.015)$.

Respiratory diagnosis, multiple devices and QoL were entered into the multivariable model, explaining $44 \%$ of the variance of poor inhaler technique (table 3 ) with a 98\% power to detect a significant difference for multiple devices. In the sensitivity analysis being less strict on critical errors based on the actual formulation, multiple devices, ACO, QoL and handgrip strength were also the strongest predictors of poor inhaler technique with only multiple devices being statistically significant $(p=0.045)$.

\section{Therapy non-adherence}

According to the 10 -item TAI score, $61 \%$ of patients were completely adherent $(n=43)$. Of the 27 non-adherents, $56 \%$ patients $(\mathrm{n}=15)$ forgot to take their medication (=sporadic non-adherence), $11 \%$ patients $(n=3)$ refused to take their medication (=deliberate non-adherence) and $33 \%(n=9)$ showed both of these patterns of nonadherence. According to the 12-item TAI score, $57 \%$ of the patients $(n=40)$ had a poor knowledge of the regimen and/or inhaler technique (=unconscious behaviour).

Table 4 shows the variables associated with therapy non-adherence. The univariable factors significantly associated with therapy non-adherence were age and smoking status. Younger patients were more likely to be non-adherent (OR 0.96; 95\% CI 0.93 to 0.99). Smoking seemed to result in a lower risk for poor therapy adherence, but the association lost significance for past smoking in multivariable analysis. Age, poor treatment 
Table 2 Number (\%) of patients performing correct steps per type of inhaler

\begin{tabular}{|c|c|c|c|c|c|}
\hline & DPI $(n=72)$ & pMDI $(n=33)$ & SMI $(n=11)$ & pMDI +VHC (n=5) & $\mathrm{AH}(\mathrm{n}=1)$ \\
\hline Make sure the mouth is empty & $72(100)$ & $33(100)$ & $11(100)$ & $5(100)$ & $1(100)$ \\
\hline Remove the cap of the device* & $72(100)$ & $32(97)$ & $10(91)$ & $5(100)$ & $1(100)$ \\
\hline Shake the device* & & $13(39)$ & & $1(20)$ & $1(100)$ \\
\hline Prepare the device correctly* & $62(86)$ & & $4(36)$ & & $1(100)$ \\
\hline Place the VHC correctly onto the device & & & & $4(80)$ & \\
\hline Keep the device upright & & $31(94)$ & & $4(80)$ & $1(100)$ \\
\hline Exhale deeply next to the device & $20(28)$ & $5(15)$ & $3(27)$ & $1(20)$ & $0(0)$ \\
\hline $\begin{array}{l}\text { Stand or sit upright and bend the head } \\
\text { slightly backwards }\end{array}$ & $13(18)$ & $2(6)$ & $3(27)$ & $3(60)$ & $0(0)$ \\
\hline $\begin{array}{l}\text { Seal the mouthpiece of the device with } \\
\text { the lips }\end{array}$ & $72(100)$ & $26(79)$ & $10(91)$ & $4(100)$ & $1(100)$ \\
\hline $\begin{array}{l}\text { Make sure to not block the air holes of } \\
\text { the device }\end{array}$ & $71(99)$ & & $11(100)$ & & $1(100)$ \\
\hline $\begin{array}{l}\text { Activate the device and manage a good } \\
\text { hand-breath coordination }\end{array}$ & & $19(58)$ & $8(73)$ & & \\
\hline Inhale vigorously and deeply* & $65(90)$ & & & & \\
\hline Inhale slowly and deeply & & $7(21)$ & $4(36)$ & & $0(0)$ \\
\hline $\begin{array}{l}\text { Activate the device and inhale deeply } \\
\text { within } 5 \mathrm{~s} \text {. after activation }\end{array}$ & & & & $5(100)$ & \\
\hline Hold breath for $10 \mathrm{~s}$ & $22(31)$ & $6(18)$ & $4(36)$ & $1(20)$ & $0(0)$ \\
\hline Inhale and exhale five times in the VHC & & & & $3(60)$ & \\
\hline $\begin{array}{l}\text { Rinse the mouth and spit out (if } \\
\text { corticosteroids) }\end{array}$ & $35(67)$ & $3(43)$ & & $2(40)$ & $1(100)$ \\
\hline
\end{tabular}

${ }^{*}$ Critical steps.

$\mathrm{AH}$, autohaler; DPI, dry powder inhaler; pMDI, pressurised metered-dose inhalers; SMI, soft mist inhalers; VHC, valved holding chamber.

knowledge and smoking status were entered into the multivariable model, explaining $21 \%$ of the variance of non-adherence (table 4). The estimated odds for non-adherence decreased by $85 \%$ for current smokers compared with never smokers, independently of age and poor treatment knowledge.

Table 3 Univariable and multivariable regression analysis of the determinants of poor inhaler technique

\begin{tabular}{|c|c|c|c|c|c|}
\hline \multirow[b]{2}{*}{ Variable } & \multirow{2}{*}{$\begin{array}{l}\text { Patients making critical } \\
\text { errors/total }(\%)\end{array}$} & \multicolumn{2}{|l|}{ Univariable } & \multicolumn{2}{|l|}{ Multivariable $^{\star}$} \\
\hline & & OR $(95 \% \mathrm{CI})$ & $P$ value & aOR (95\% Cl) & $P$ value \\
\hline Age (years) & & 1.01 (0.98 to 1.04$)$ & 0.640 & & \\
\hline \multicolumn{6}{|l|}{$\begin{array}{l}\text { Respiratory } \\
\text { diagnosis }\end{array}$} \\
\hline Asthma & $11 / 31(35)$ & Ref. & & Ref. & \\
\hline COPD & $16 / 27(59)$ & 2.64 (0.91 to 7.66$)$ & 0.073 & 2.43 (0.66 to 8.99$)$ & 0.184 \\
\hline ACO & $9 / 12(75)$ & 5.45 (1.22 to 24.43$)$ & 0.027 & 7.06 (1.15 to 43.35$)$ & 0.035 \\
\hline $\begin{array}{l}\text { Multiple vs single } \\
\text { device }\end{array}$ & $25 / 32(78)$ vs $11 / 38(29)$ & 8.77 (2.94 to 26.14$)$ & $<0.001$ & 11.68 (3.29 to 41.51$)$ & $<0.001$ \\
\hline Quality of life & & 0.96 (0.93 to 1.00$)$ & 0.037 & 0.96 (0.93 to 1.01$)$ & 0.087 \\
\hline \multicolumn{6}{|c|}{ Received inhaler instruction before from pharmacist/physician } \\
\hline Never vs ever & $3 / 5(60)$ vs $33 / 65$ (51) & $1.45(0.23$ to 9.29$)$ & 0.692 & & \\
\hline Handgrip strength & o predicted & 0.99 (0.97 to 1.01$)$ & 0.240 & & \\
\hline
\end{tabular}

Significant estimates $(\mathrm{p}<0.05)$ are indicated in bold.

*Nagelkerke R²: 0.437; Hosmer and Lemeshow Goodness-of-fit test p-value: 0.575; correctly classified: $75.7 \%$.

ACO, asthma-COPD overlap; aOR, adjusted OR; ; COPD, chronic obstructive pulmonary disease. 


\begin{tabular}{|c|c|c|c|c|c|}
\hline Variable & Non-adherent patients/total (\%) & OR $(95 \% \mathrm{Cl})$ & $P$ value & aOR $(95 \% \mathrm{Cl})$ & $P$ value \\
\hline Age (years) & & 0.96 (0.93 to 0.99$)$ & 0.017 & 0.98 (0.94 to 1.01$)$ & 0.228 \\
\hline \multicolumn{6}{|l|}{ Respiratory diagnosis } \\
\hline Asthma & $14 / 31(45)$ & Ref. & & & \\
\hline COPD & $8 / 27(30)$ & 0.51 (0.17 to 1.52$)$ & 0.227 & & \\
\hline $\mathrm{ACO}$ & $5 / 12(42)$ & 0.87 (0.23 to 3.34$)$ & 0.836 & & \\
\hline Multiple vs single device & $13 / 32(41)$ vs $14 / 38(37)$ & 1.17 (0.45 to 3.08$)$ & 0.746 & & \\
\hline Quality of life & & 1.00 (0.96 to 1.03$)$ & 0.759 & & \\
\hline High vs low education & $17 / 42(40)$ vs $10 / 28(36)$ & 1.22 (0.46 to 3.29$)$ & 0.689 & & \\
\hline Poor treatment knowledge & $17 / 40(43)$ vs $10 / 30(33)$ & 1.48 (0.55 to 3.96$)$ & 0.436 & 2.89 (0.81 to 10.24$)$ & 0.100 \\
\hline Adverse drug events vs no & $11 / 30(37)$ vs $16 / 40(40)$ & 0.87 (0.33 to 2.30$)$ & 0.777 & & \\
\hline \multicolumn{6}{|l|}{ Smoking status } \\
\hline Never & $14 / 24(58)$ & Ref. & & Ref. & \\
\hline Past & $10 / 32(31)$ & 0.32 (0.11 to 0.98$)$ & 0.046 & $0.32(0.07$ to 1.40$)$ & 0.130 \\
\hline Current & $3 / 14(21)$ & 0.19 (0.04 to 0.88$)$ & 0.034 & $0.15(0.02$ to 0.96$)$ & 0.045 \\
\hline
\end{tabular}

Significant estimates $(\mathrm{p}<0.05)$ are indicated in bold.

${ }^{\star}$ Nagelkerke $R^{2}$ : 0.210; Hosmer and Lemeshow goodness-of-fit test p value: 0.376 ; correctly classified: $71.4 \%$.

ACO, asthma-COPD overlap; aOR, adjusted OR; ; COPD, chronic obstructive pulmonary disease; TAl, Test of the Adherence to Inhalers.

When also defining inhaler overuse as poor adherence, half of the patients were adherent having an mMPR between $80 \%$ and $120 \%(51 \%, \mathrm{n}=36)$. Of the 34 nonadherent patients, $68 \%$ of the patients $(n=23)$ demonstrated underuse and $32 \%(\mathrm{n}=11)$ inhaler overuse. The drugs being overused were LABA/ICS $(n=5)$, LABA $(n=3)$, LAMA/LABA/ICS $(n=2)$ and LABA/LAMA $(\mathrm{n}=1)$. Table 5 shows the variables associated with poor therapy adherence according to the mMPR. Only higher education level was significantly associated with poor adherence in univariable analyses. Respiratory diagnosis, education level, smoking status and multiple devices were entered into the multivariable model, explaining $39 \%$ of the variance of poor adherence (table 5). ACO (adjusted OR, aOR $0.13 ; 95 \%$ CI 0.02 to 0.97 ), higher education (aOR 14.81; 95\% CI 3.21 to 68.43 ) and current smoking

Table 5 Univariable and multivariable regression analysis of the determinants of poor adherence (mMPR $<80 \%$ or mMPR $>120 \%)$

\begin{tabular}{|c|c|c|c|c|c|}
\hline \multirow[b]{2}{*}{ Variable } & \multirow[b]{2}{*}{ Non-adherent patients/total (\%) } & \multicolumn{2}{|l|}{ Univariable } & \multicolumn{2}{|l|}{ Multivariable* } \\
\hline & & OR $(95 \%$ Cl) & $P$ value & aOR $(95 \% \mathrm{Cl})$ & $P$ value \\
\hline Age (years) & & 0.99 (0.97 to 1.02$)$ & 0.685 & & \\
\hline \multicolumn{6}{|l|}{ Respiratory diagnosis } \\
\hline Asthma & $17 / 31(55)$ & Ref. & & Ref. & \\
\hline COPD & $13 / 27(48)$ & 0.76 (0.27 to 2.15$)$ & 0.611 & 0.69 (0.15 to 3.05$)$ & 0.620 \\
\hline $\mathrm{ACO}$ & 4/12 (33) & 0.41 (0.10 to 1.66$)$ & 0.212 & $0.13(0.02$ to 0.97$)$ & 0.047 \\
\hline Multiple vs single device & $13 / 32$ (41) vs $21 / 38(55)$ & 0.55 (0.21 to 1.44$)$ & 0.224 & 0.39 (0.12 to 1.28$)$ & 0.122 \\
\hline Quality of life & & 1.03 (0.99 to 1.06$)$ & 0.129 & & \\
\hline High vs low education & $27 / 42$ (64) vs $7 / 28(25)$ & 5.40 (1.87 to 15.63$)$ & 0.002 & 14.81 (3.21 to 68.43$)$ & 0.001 \\
\hline Poor treatment knowledge & $18 / 40(45)$ vs $16 / 30(53)$ & 0.72 (0.28 to 1.85$)$ & 0.491 & & \\
\hline Adverse drug events vs no & $14 / 30$ (47) vs $20 / 40(50)$ & 0.88 (0.34 to 2.26$)$ & 0.782 & & \\
\hline \multicolumn{6}{|l|}{ Smoking status } \\
\hline Never & $11 / 24(46)$ & Ref. & & Ref. & \\
\hline Past & $14 / 32(44)$ & 0.92 (0.32 to 2.66$)$ & 0.877 & 2.25 (0.47 to 10.73$)$ & 0.309 \\
\hline Current & 9/14 (64) & 2.13 (0.55 to 8.26$)$ & 0.275 & 28.92 (2.65 to 315.91$)$ & 0.006 \\
\hline
\end{tabular}

Significant estimates $(p<0.05)$ are indicated in bold.

*Nagelkerke $\mathrm{R}^{2}$ : 0.394; Hosmer and Lemeshow goodness-of-fit test $p$-value: 0.866 ; correctly classified: $72.9 \%$.

ACO, asthma-COPD overlap; aOR, adjusted OR; ; COPD, chronic obstructive pulmonary disease; mMPR, modified medication possession ratio. 
(aOR 28.92; 95\% CI 2.65 to 315.91) were associated with poor adherence. Compared with patients with asthma, patients with ACO were more therapy adherent. Interestingly, this was driven by both less inhaler underuse $(25 \%$ vs $39 \%$ ) as inhaler overuse (8\% vs $16 \%$ ) among patients with ACO versus patients with asthma respectively. The proportion of poor adherence was 64\% (16 underusers and 11 overusers) in higher educated patients compared with $25 \%$ (all seven underusers) in lower educated patients. More than half of the higher educated patients had a poor treatment knowledge $(52 \%, \mathrm{n}=22)$ compared with $64 \%(n=18)$ of the lower educated patients.

\section{DISCUSSION}

In our community pharmacy-based study, half of patients made critical errors in using at least one of their inhalers. Additionally, non-adherence occurred in more than one third of patients and occurred in up to one half of the patients, when also taking overuse into account. The use of multiple devices was the strongest determinant of a poor inhaler technique. Another factor significantly affecting poor inhaler technique was a diagnosis of ACO. The poor adherence in smoking and highly educated patients seemed to be driven by their increased risk for inhaler overuse.

The overall score on inhaler technique was low, with half of patients making critical errors and almost nobody showing a perfect inhaler technique. The systematic review of Sanchis et alalready pointed to a very low overall prevalence of correct inhaler technique of $31 \%$ of the patients $(28 \%-35 \%){ }^{8}$ By the larger number of assessed steps in our checklist, we might have been even more strict in concluding a perfect inhaler technique. ${ }^{29}$ The most common error for all devices was the posture, more specific forgetting to bend the head slightly backwards. This is an important (but non-critical) step that minimises impaction of the drug particles in the oropharynx, resulting in a higher dose deposited in the lungs. ${ }^{30}$

The strongest determinant of a poor inhaler technique was the use of multiple devices. This finding is in agreement with prior research. ${ }^{29}$ The use of multiple devices confuses patients since different inhaler techniques are required.$^{31}$ However, a combination of a pMDI and a DPI is sometimes prescribed because short-acting bronchodilators are only reimbursed in pMDI in Belgium. Our results suggest a DPI to be the most user-friendly device as it has the lowest proportion of patients who made critical errors. This assumption has been confirmed by other studies. ${ }^{32} 33$

Other significant determinants of a poor inhaler technique were a diagnosis of ACO and a lower QoL. In our study, COPD and ACO patients tend to make more critical errors than asthma patients. Our finding is in agreement with some studies showing that patients with asthma had a significantly better inhaler technique than patients with COPD,${ }^{113}$ while other studies have not observed this association, ${ }^{912}$ or found an association that disappeared after adjustment for device type, age and level of instruction. ${ }^{18}$ A possible explanation is that asthma patients feel more direct benefit or are more satisfied with their inhaler. ${ }^{34}$ To our knowledge, the association with ACO has not yet been described. This finding could be explained by ACO patients being more likely to have comorbidities, which have been associated with poorer inhaler technique. ${ }^{17} 35$ Furthermore, patients with a lower QoL tended to make more critical errors. This is in accordance with prior research that observed that patients with emotional problems were more likely to make inhalation mistakes. ${ }^{9}$ The association between QoL and poor inhaler technique did not change after adjusting for the use of antidepressants. However, we had no information about depressive symptoms or personality type.

We could not replicate that grip strength was a significant determinant of inhaler technique. ${ }^{27}$ However, only one patient on DPI and pMDI had a mean hand grip strength below $10 \mathrm{~kg}$ in our study, which is the minimum grip strength (as a proxy for inspiratory flow) for DPI. ${ }^{36}$ Unlike previous research, ${ }^{12}{ }^{13}$ we could not find an association between patients who never received inhaler instructions from their pharmacist or physician and critical errors. This may be due to the fortunately low number of patients who have never been instructed before, and missing information on the number of previous instructions and how long ago these were. Nevertheless a continuous assessment of inhaler technique remains crucial since a poor technique causes poor disease control and patients may have forgotten the instructions at their first dispensing.

Poor adherence is influenced by various factors, ${ }^{37}$ and younger age was the most important one in univariable analyses. This finding is in accordance with other research showing that older age relates to better adherence. ${ }^{15}$ Overall, therapy adherence according to the TAI $(61 \%)$ was slightly better than the estimated WHO adherence in chronic conditions $(50 \%),{ }^{7}$ but could be overestimated, since patients may give socially desirable answers. Therefore, we also objectively evaluated adherence based on the pharmacy dispensing data. The TAI questionnaire is considered as a reliable tool to assess adherence to inhalers. ${ }^{21}$ However, the TAI questionnaire only detects underuse but does not capture overuse of inhalers. This means that overusing patients could be classified as adherent patients according to the TAI. Therefore, the differences between the TAI and mMPR (based on the pharmacy medication history) were evaluated, which increased our insight into the association of smoking and higher education with inhaler adherence.

Although univariable analysis showed that smoking seemed to result in a lower risk for poor therapy adherence, the association with past smoking was not significant in the multivariable analysis. While this observation is contradictory to previous studies ${ }^{15}$ it might reflect a higher need for, or perceived benefit of, symptom relief among (ever) smokers in this cohort. As current smokers seemed more symptomatic and tend to overuse 
medication, it resulted in a false conclusion that smoking lowers the risk for poor therapy adherence according to the TAI definition, which was countered in the mMPR analysis.

Moreover, a higher education level was the strongest determinant of non-adherence (mMPR $<80 \%$ or mMPR $>120 \%$ ). This finding was contradictory to 4 out of 10 results included in a systematic review, ${ }^{15}$ but similar to another study. ${ }^{38}$ The authors attributed this to more trust in physicians' advice by less educated patients. ${ }^{38}$ Unfortunately, we can add from our study that the proportion of patients among higher educated patients with a good treatment knowledge was still not higher than patients with a poor treatment knowledge. Moreover, the overusers were all higher educated patients.

A major strength of our study was the evaluation of a large number $(n=122)$ of real-life inhaler technique demonstrations. Furthermore, adherence was assessed through a self-reported questionnaire and by pharmacy dispensing data. The mMPR was calculated on a standardised dosing and not individual regimens. For generalisability, the participants inclusion criteria were broad and also patients with ACO were included. However, the most vulnerable patients such as patients with cognitive deficits who do not come to the pharmacy themselves may be underrepresented. No spirometry results were available to confirm the diagnosis. However, this limitation supports the pragmatic framework. Another limitation of this study was the relatively small sample size of participating patients. This hampered the ability of the inclusion of more variables in the model to avoid overfitting.

In conclusion, our study shows that the use of multiple devices and a diagnosis of ACO are independently and significantly associated with a poor inhaler technique. Therapy adherence was poor in patients with asthma compared with those with asthma-COPD overlap, and smoking and highly educated patients seemed to be at increased risk for inhaler overuse. Given the important role of therapy adherence and a correct inhaler technique in disease control, these findings emphasise the need for patient education and aiming uniformity in the inhaler device.

Acknowledgements We would like to thank Sofie Wouters for contribution to the investigation, and all the patients and pharmacists for their participation.

Contributors LL was responsible for the study concept and design. PvdW assisted in data collection and performed some analyses. AV analysed the data under supervision of LL. AV drafted the manuscript and LL, BP and PvdW critically reviewed the manuscript.

Funding This research was funded by Ghent University, and the Chiesi Award for a socially relevant project awarded by the Belgian Respiratory Society (BeRS).

Competing interests None declared.

Patient and public involvement statement Patients and/or the public were not involved in the design, or conduct, or reporting, or dissemination plans of this research.

\section{Patient consent for publication Not required.}

Ethics approval The study protocol was approved by the Medical Ethics Committee of Ghent University Hospital (B670201835229). All patients completed an informed consent form before participation to the study. Furthermore, personal data was pseudonymised by using a patient code in the dataset and separating identifiable documents.

Provenance and peer review Not commissioned; externally peer reviewed.

Data availability statement Data are available on reasonable request. The datasets generated during and/or analysed during the current study are available from the corresponding author on reasonable request.

Open access This is an open access article distributed in accordance with the Creative Commons Attribution Non Commercial (CC BY-NC 4.0) license, which permits others to distribute, remix, adapt, build upon this work non-commercially, and license their derivative works on different terms, provided the original work is properly cited, appropriate credit is given, any changes made indicated, and the use is non-commercial. See: http://creativecommons.org/licenses/by-nc/4.0/.

\section{ORCID iDs}

Anna Vanoverschelde http://orcid.org/0000-0002-5902-917X

Barbara Putman http://orcid.org/0000-0001-9248-3481

Lies Lahousse http://orcid.org/0000-0002-3494-4363

\section{REFERENCES}

1 World Health Organization. Chronic respiratory diseases, 2017. Available: https://www.who.int/respiratory/en/

2 Global Initiative for Chronic Obstructive Lung Disease. Global strategy for the diagnosis, management and prevention of COPD: 2020 report., 2020. Available: https://goldcopd.org/wp-content/ uploads/2019/11/GOLD-2020-REPORT-ver1.0wms.pdf

3 Global initiative for asthma. Global strategy for asthma managment and prevention., 2020. Available: https://ginasthma.org/wp-content/ uploads/2020/06/GINA-2020-report_20_06_04-1-wms.pdf

4 Levy ML, Dekhuijzen PNR, Barnes PJ, et al. Inhaler technique: facts and fantasies. A view from the aerosol drug management improvement team (admit). NPJ Prim Care Respir Med 2016;26:16017.

5 van Boven JFM, de Jong-van den Berg LTW, Vegter S. Inhaled corticosteroids and the occurrence of oral candidiasis: a prescription sequence symmetry analysis. Drug Saf 2013;36:231-6.

6 Yang IA, Clarke MS, Sim EHA, et al. Inhaled corticosteroids for stable chronic obstructive pulmonary disease. Cochrane Database Syst Rev 2012:CD002991.

7 World Health Organization. Adherence to long-term therapies: evidence for action., 2003. Available: https://www.who.int/chp/ knowledge/publications/adherence introduction.pdf

8 Sanchis J, Gich I, Pedersen S, et al. Systematic review of errors in inhaler use: has patient technique improved over time? Chest 2016;150:394-406.

9 Hesselink AE, Penninx BW, Wijnhoven HA, et al. Determinants of an incorrect inhalation technique in patients with asthma or COPD. Scand J Prim Health Care 2001;19:255-60.

10 Barbara S, Kritikos V, Bosnic-Anticevich S. Inhaler technique: does age matter? A systematic review. Eur Respir Rev 2017;26:170055.

11 Buckley D. Assessment of inhaler technique in general practice. Ir J Med Sci 1989;158:297-9.

12 Rootmensen GN, van Keimpema ARJ, Jansen HM, et al. Predictors of incorrect inhalation technique in patients with asthma or COPD: a study using a validated videotaped scoring method. $J$ Aerosol Med Pulm Drug Deliv 2010;23:323-8.

13 Perumal R, Leite M, van Zyl-Smit RN. The relationship between clinical trial participation and inhaler technique errors in asthma and COPD patients. Int J Chron Obstruct Pulmon Dis 2020;15:1217-24.

14 Mäkelä MJ, Backer V, Hedegaard M, et al. Adherence to inhaled therapies, health outcomes and costs in patients with asthma and COPD. Respir Med 2013;107:1481-90.

15 Dima AL, Hernandez G, Cunillera O, et al. Asthma inhaler adherence determinants in adults: systematic review of observational data. Eur Respir J 2015;45:994-1018.

16 Plaza V, López-Viña A, Entrenas LM, et al. Differences in adherence and Non-Adherence behaviour patterns to inhaler devices between COPD and asthma patients. COPD 2016;13:547-54.

17 Dalcin PdeTR, Grutcki DM, Laporte PP, et al. Factors related to the incorrect use of inhalers by asthma patients. J Bras Pneumol 2014;40:13-20.

18 Melani AS, Bonavia M, Cilenti V, et al. Inhaler mishandling remains common in real life and is associated with reduced disease control. Respir Med 2011;105:930-8.

19 Vanoverschelde A, van der Wel P, Putman B, et al. A pragmatic randomized controlled trial to improve inhaler technique using mHealth. Clin Transl Allergy 2020;10:59. 
20 Usmani OS, Lavorini F, Marshall J, et al. Critical inhaler errors in asthma and COPD: a systematic review of impact on health outcomes. Respir Res 2018;19:10.

21 Plaza V, Fernández-Rodríguez C, Melero C, et al. Validation of the 'Test of the Adherence to Inhalers' (TAI) for Asthma and COPD Patients. J Aerosol Med Pulm Drug Deliv 2016;29:142-52.

22 Scientific Committee for the tai project and Chiesi. Test of adherence to inhalers. Available: http://www.taitest.com/

23 Hess LM, Raebel MA, Conner DA, et al. Measurement of adherence in pharmacy administrative databases: a proposal for standard definitions and preferred measures. Ann Pharmacother 2006;40:1280-8.

24 Enright PL, Kronmal RA, Manolio TA, et al. Respiratory muscle strength in the elderly. correlates and reference values. cardiovascular health study Research Group. Am J Respir Crit Care Med 1994;149:430-8.

25 Bohannon RW, Peolsson A, Massy-Westropp N, et al. Reference values for adult grip strength measured with a Jamar dynamometer: a descriptive meta-analysis. Physiotherapy 2006;92:11-15.

26 Rabin R, de Charro F. EQ-5D: a measure of health status from the EuroQol group. Ann Med 2001;33:337-43.

27 Gray SL, Williams DM, Pulliam CC, et al. Characteristics predicting incorrect metered-dose inhaler technique in older subjects. Arch Intern Med 1996;156:984-8.

28 Jin J, Sklar GE, Min Sen Oh V, et al. Factors affecting therapeutic compliance: a review from the patient's perspective. Ther Clin Risk Manag 2008;4:269-86.

29 Chrystyn $\mathrm{H}$, van der Palen J, Sharma R, et al. Device errors in asthma and COPD: systematic literature review and meta-analysis. NPJ Prim Care Respir Med 2017;27:22.
30 Visser R, Wind M, de Graaf BJ, et al. The effect of body posture during medication inhalation on exercise induced bronchoconstriction in asthmatic children. Respir Med 2015;109:1257-61.

31 van der Palen J, Klein JJ, van Herwaarden CL, et al. Multiple inhalers confuse asthma patients. Eur Respir J 1999;14:1034-7.

32 O'Connor BJ. The ideal inhaler: design and characteristics to improve outcomes. Respir Med 2004;98 Suppl A:S10-16.

33 Ramadan WH, Sarkis AT. Patterns of use of dry powder inhalers versus pressurized metered-dose inhalers devices in adult patients with chronic obstructive pulmonary disease or asthma: an observational comparative study. Chron Respir Dis 2017;14:309-20.

34 Plaza V, Giner J, Curto E, et al. Determinants and differences in satisfaction with the inhaler among patients with asthma or COPD. $J$ Allergy Clin Immunol Pract 2020;8:645-53.

35 Yawn BP, Colice GL, Hodder R. Practical aspects of inhaler use in the management of chronic obstructive pulmonary disease in the primary care setting. Int J Chron Obstruct Pulmon Dis 2012;7:495-502.

36 Frohnhofen $\mathrm{H}$, Hagen $\mathrm{O}$. Handgrip strength measurement as a predictor for successful dry powder inhaler treatment: application in older individuals with COPD. Z Gerontol Geriatr 2011;44:245-9.

37 Sanduzzi A, Balbo P, Candoli P, et al. Copd: adherence to therapy. Multidiscip Respir Med 2014;9:60.

38 Aredano I, de Blasio F, Berchialla P, et al. Determinants of self-reported adherence to inhaler therapy in patients with chronic obstructive pulmonary disease. Multidiscip Respir Med 2020;15:654. 